\title{
ANALISIS USAHATANI PENERAPAN SISTEM TANAM JAJAR LEGOWO TERHADAP PENDAPATAN PETANI PADI DI KELURAHAN KEMPAS JAYA KECAMATAN KEMPAS KABUPATEN INDRAGIRI HILIR
}

\author{
Oktarian Priyatno \\ Program Studi Agribisnis Fakultas Pertanian UNISI \\ Email : Oktarian@gmail.com
}

\begin{abstract}
ABSTRAK
Tujuan penelitian adalah (1) untuk mengetahui seberapa besar pendapatan petani padi dengan mengguanakan sistem tanam jajar legowo, (2) untuk mengetahui efesiensi usahatani padi dengan sistem tanam jajar legowo di Kelurahan Kempas Jaya. Metode yang digunakan adalah metode survey, Jumlah sampel pada penelitian berjumlah 24 orang petani padi. Menunjukan (1) bahawa pendapatan kotor rata-rata petani sebersar Rp. 23.151.785,71 /Ha/MT dan pendapatan bersih sebesar Rp. 11.796.378,97 / Ha serta pendapatan kerja keluarga sebesar Rp. 10.622.905,48 / Ha/MT, (2) (RCR) ini berati bahwa usahata tani padi sistem tanam jajar legowo di Kelurahan Kempas Jaya dapat dilaksanakan dengan efesien dimana setiap Rp. 1.00 biaya yang dikeluarkan akan menghasilkanpenerimaan sebesar 2,04.
\end{abstract}

Kata Kunci : Padi sawah, Jajar Legowo

\begin{abstract}
ABSTRACK
The research purposes are (1) To know Revenue of paddy farmer with appliying jajar legowo system at vilage of Kempas, (2) to know effeciency of paddy farmer at Village Kempas Jaya. The method used is survey. Number of sampel 24 farmer The result ot research showed that (1) average Total revenue Rp. 23.151.785,71 / Ha/planting season, Benefit Rp. 11.796.378,97 /Ha/ planting seson (2) Revenue cost ratio (RCR) is 2.04 it's mean that farming of paddy is efficient where Rp. 1.00 cost issued will received total Revenue of Rp.2.04
\end{abstract}

Key words : Paddy, Jajar Legowo

\section{PENDAHULUAN}

Upaya
produksi tanaman di hadapkan
berbagai kendala dan masalah.
Kekeringan dan banjir yang tidak
jarang mengancam produksi di
beberapa daerah, penurunan
produksifitas lahan pada sebagian
areal pertanaman, hama penyakit
tanaman yang terus berkembang, dan

tingkat kehilangan hasil pada saat dan setelah panen yang masih tinggi merupakan masalah yang perlu dipecahkan. Kini dan kedepan, upaya peningkatan produksi tanaman pangan perlu di tingkatkan dengan efesiensi, dan daya saing produksi, dan kelestarian lingkungan. Hal ini penting artinya dalam upaya peningkatan pendapatan petani, 
ketahanan pangan dan keberlanjutan usahatani yang merupakan isu sentral pembangunan pertanian (Suyamto, 2007).

Pertanian produktivitas usahatani tanaman padi sangan di butuhkan dalam rangka pemenuhan rakyat Indonesia. Dimana padi merupakan bahan pokok makanan rakyat indonesia. Untuk itu balai pengkajian teknologi pertanian menciptakan komponen teknologi PTT yaitu pengelolaan tanaman terpadu yang terdiri dari (1) farietas bibit unggul, (2) persemaian yang baik, (3)pengolahan tanah, (4) penanaman bibit muda, (5) sistim tanam Legowo, (6) perairan yang teratur, (7) pemupukan teratur dan berimbang, (9) pengendalian hama penyakit, (10) panen dan pasca panen. Kenersegian komponen PTT mampu meningkatkan produktifitas padi.

Sistemtanam legowo merupakan rekayasa teknologi yang di tujukan untuk memperbaiki produktifitas usahatani padi. Teknologi ini merupakan perubahan dari teknologijarak tanam legal menjadi jarak jajar tanam legowo. Di antara kelompok barisan tanam padi terdapat lorong yang lurus dan memanjang sepanjang barisan. Jarak antar kelompok barisan (lorong) bisa mencapai $50 \mathrm{~cm}, 60 \mathrm{~cm}$ tergantung pada kesuburan tanah (suriapermana, et. al., 1990). Lebih lanjut Imran dan Syarifudin (2005) mengemukakan bahwa sistim jajar tanam legowo adalah penanaman padi yang di atur sedemikian rupa dengan lorong atau ruang terbuka yang cukup lebar. Cara tanam padi sistem jajar legowo bertujuan untuk memperbaiki produktifitas usahatani padi legowo di ambil dari bahasa Jawa Banyumas terdiri dari kata "Lego" dan "dowo"lego berati luas dan dowo berati memanjang jadi diantara kelompok tanaman padi terdapat lorong yang luasdan memanjang sepanjang barisan tanaman.

Keuntungan yang di peroleh dari penerapan sistem ini adalah peningkatan produksi persatuan luas yang akan meningkatkan pendapatan yang di trimapetani. Hal ini sesuai pendapat Mujisihono, et al., (2001), bahwa keuntungan dari sistem jajar tanam legowoadalah menjadikan semua tanaman atau lebih banyak tanaman menjadi tanaman pinggir. Tanaman pinggir akan memperoleh sinar matahari yang lebih banayak dan sirkulasi udara yang lebih baik unsur hara yang lebih merata serta mempermudah pemeliharaan tanaman. Hasil penelitian Mirsan (2014) bahwa penerapan sistem tanam jajar legowo berpengaruh nyata terhadap komponen hasil gabah kering panen dan dapat meningkatkan hasil gabah kering panen sekitar 19,90-22\%.

Salah satu daerah penghasil komoditi padi adalah Kelurahan Kempas Jaya Kecamatan Kempas Kabupaten Indragiri Hilir yang telah giat melaksanakan intensifikasi padi sawah dengan penerapan teknologi sistem tanam jajar legowo, bahkan di Kelurahan Kempas Jaya telah menerapkan Indeks Pertanaman (IP) 200 atau penanaman dilakukan dua kali dalam setahun,diKelurahan Kempas. Tujuan penelitian ini adalah untuk mengetahui pendapatan usahatani Padi dengan sistem tanam jajar Legowo dan untuk mengetahui efesiensi usahatani padi dengan sistem tanam jajar Legowo di Kelurahan Kempas Jaya. 


\section{METODOLOGI PENELITIAN}

\subsection{Tempat Dan waktu Penelitian}

Penelitian akan dilaksanakan di Kelurahan Kempas jaya, Kecamatan Kempas Kabupaten Indragiri Hilir, alasan dipilihnya tempat ini sebagai tempat penelitian karena merupakan tempat sentral gabah dan tempat dimana petani telah banyak menerapkan sistem jajar tanam legowo. namun belum dilakukan analisis. Penelitian akan dilaksanakan selam 3 bulan yaitu bulan September 2016 - November 2016.

\subsection{Metode Pengambilan Sampel}

Populasi dalam penelitian ini adalah seluruh petani padi yangada di kelurahan Kempas Jaya yaitu yang berjumlah 465 orang, yang terdiri dari 12 kelompok tani, dan dari 12 kelompok tani hanya di ambil satu kelompok 2 orang jadi keseluruhan sampel yang digunakan berjumlah 24 orang, sampel penelitian ini di ambil menggunakan purposive samplingdikarnakan petani masih ada yang menggunakan sistem tanam tegal ( non legowo).

\subsection{Metode Analisis Data}

Data yang di kumpulkan diolah dan dianalisis analisis meliputi struktur biaya pada sistim jajar tanam legowo. Besarnya biaya total yang di keluarkan petani secara matematis di nyatakan sebagai berikut:

$\mathrm{TC}=\mathrm{FC}+\mathrm{VC}$

Dimana:

$\mathrm{TC}=$ Biaya total (total cost) (Rp/musim tanam).
$\mathrm{FC}=$ Biaya tetap (fixed cost) (Rp/musim tanam).

$\mathrm{VC}=$ Biaya variabel (variable cost) (Rp/musim tanam).

Besarnya pendapatan koto dari usaha tanaman padi sawah sealama musim tanam, secara matimatis dapat di tulis sebagai berikut

$\mathrm{TR}=\mathrm{P} \cdot \mathrm{Q}$

Dimana:

TR = Pendapatan Kotor (total revenue) (Rp/musim tanam).

$\mathrm{P} \quad=$ Produksi $(\mathrm{Kg}) / \mathrm{musim}$ tanam.

Q = Harga produksi (price) $/ \mathrm{Rp} / \mathrm{Kg}$ ).

Untuk mengetahui besarnya pendapatan bersih dapat digunakan rumus sebagai berikut: pendapatan

$\pi \quad=\mathrm{TR}-\mathrm{TC}$

Dimana:

$\pi \quad=$ Pendapatan bersih (Rp/MT)

$\mathrm{TR}=$ Pendaatan Kotor $(\mathrm{Rp} / \mathrm{MT})$

$\mathrm{TC}=$ Total $\operatorname{Cost}(\mathrm{Rp} / \mathrm{MT})$

Untuk mengetahui kelayakam usaha tani padi sawah dapat digunakan rumus sebagai berikut:

$\mathrm{RCR}=\mathrm{TR} / \mathrm{TC}$

Dimana

$\mathrm{RCR}=$ Revenue Cost Ratio; (Rp/MT)

$\mathrm{TR}=$ Pendapatan Kotor $(\mathrm{Rp} / \mathrm{MT})$

$\mathrm{TC}=$ Total Biaya $(\mathrm{Rp} / \mathrm{MT})$

Untuk mengetahui kriteria pengambilan keputusan dapat digunakan rumus sebagai berikut: 
a. Jika R/C > 1, maka usahatani mengalami keuntungan karena penerimaan lebih besar dari biaya.

b. Jika R/C < 1, maka usahatani mengalami kerugian karena penerimaan lebih kecil dari biaya.

c. Jika $\mathrm{R} / \mathrm{C}=1$, maka usahatani mengalami impas karena penerimaansama dengan biaya.

\section{HASIL DAN PEMBAHASAN}

\subsection{Sarana produksi}

$$
\begin{array}{ccc}
\text { Kegiatan usahatani } & \text { yang } \\
\text { dikelola petani } & \text { tidak } & \text { akan }
\end{array}
$$

memberikan hasil yang baik tanpa didukung oleh penggunaan sarana produksi. Dalam usahatani padi sarna yang digunakan oleh petani responden terdiri dari benih, pupuk, pestisida dan herbisida. Pengadaan dan penyaluran sarana produksi merupakan salah satu faktor penting untuk keberhasilan pengolahan usahatni sistem tanam jajar legowo seperti bibit, pupuk, pestisida serta alat-alat pertanian lainnya. Untuk lebih jelasnya dalam jumlah penggunaan sarana produksi pada kegiatan produksi padi dapat dilihat pada tabel 1 .

Tabel 1. Biaya produksi pendapatan dan efesiensi usahatani sistem tanam jajar legowo di kelurahan kempas jaya kec kempas ( rata-rata/

\begin{tabular}{|c|c|c|c|}
\hline No & Jenis Sarana Produksi & $\begin{array}{c}\text { Jumlah Penggunaan rata- } \\
\text { rata/Ha }(\mathrm{Kg})\end{array}$ & Nilai (Rp) \\
\hline 1 & Benih & & $183.673,47$ \\
\hline \multirow[t]{4}{*}{2} & Pupuk (Kg) & & \\
\hline & a. Urea & 194 & 6.190 .48 \\
\hline & b. SP 36 & 164 & 7.857 .14 \\
\hline & c. Phoska & 223 & 7.619 .05 \\
\hline \multirow[t]{5}{*}{3} & Pestisida (ltr) & & \\
\hline & a. Applaud & 2 & \\
\hline & b. Smack Down & 2 & 107.142 .86 \\
\hline & c. Sdabas & 2 & 107.142 .86 \\
\hline & d. Rakus & 4 & 59.523 .81 \\
\hline \multirow[t]{4}{*}{4} & Herbisida (ltr) & & \\
\hline & a. Roundup & 7 & 273.809 .52 \\
\hline & b. Paratop & 4 & 209.523.81 \\
\hline & c. Ally Plus & 11 & 128.571 .43 \\
\hline
\end{tabular}
Ha/MT)

Sumber: Data Primer Diolah, 2016

\subsection{Alat-alat Pertanian}

Untuk menunjang keberhasilan dalam pengolahan usahatani maupun kegiatan panen, maka penggunaan alat-alat pertanian sangat diperlukan oleh petani, adapun jenis alat-alat pertanian yang digunakan oleh petani responden antara lain, Parang, Handsprayer, Cangkul, Sabib bergerigi, Sabit biasa, Hend Traktor, Hendtreaser. Alat-alat pertanian ini biasanya tidak habis dalam sekali pakai dalam satu kali produksi, jadi yang dihitung hanya nilai penyusutannya saja, 
kecuali Hendtraktor dan hendtreaser karna petani hanay menyewa dan meminjam dengan kelompok tani. Nilai penyusutan diperoleh dari selisih harga beli dengan nilai sisa
$20 \%$ dan untuk lebih jelasnya jumlah penggunaan alat dan harga penyusutan alat pada usahatani dapat dilihat pada tabel 2 .

Tabel 2. Jumlah Penggunaan, Harga dan NilainPenyusutan Alat Pada Usahatani Padi di Kelurahan Kempas Jaya (/Ha)

\begin{tabular}{llrr}
\hline No & Jenis Alat & Jumlah Unit (Ha) & \multicolumn{2}{c}{ Nilai Penyusutan } \\
& & \multicolumn{2}{c}{ / Musim } \\
$\mathbf{1}$ & Parang & 4 & 18.799 .60 \\
$\mathbf{2}$ & Handsprayer & 3 & 119.285 .71 \\
$\mathbf{3}$ & Cangkul & 4 & 22.500 .00 \\
$\mathbf{4}$ & Sabib Bergerigi & 4 & 11.047 .62 \\
$\mathbf{5}$ & Sabit Biasa & 4 & 12.285 .71 \\
\hline Rata-rata & 19 & 177.728 .17 \\
\hline
\end{tabular}

Sumber: Data Primer 2016

Pada tabel 2 bahwa jumlah penggunaan alat-alat pertanian dengan rata-rata penggunaan sebanyak 4 unit, rata-rata biaya penyusutan alat yang digunakan oleh petani pemusim panen adalah Rp.177.728,17 permusim tanam besarnya biaya ini dipengaruhi oleh jumlah alat yang digunakan serta harga per unit dan jangka waktu usia alat tersebut.

Alat dan mesin pertanian atau yang biasanya disingkat dengan Alsintan merupakan alat-alat yang digunakan dalam bidang pertanian untuk melancarkan dan mempermudah petani dalam mengelola lahan dan hasil-hasil pertanian alat dan mesin pertanian sangat lah berperan penting dalam berbagai kegiatan pertanian diantaranya adalah menyediakan tenaga untuk daerah yang kekurangan tenaga kerja antisipasi minat kerja dibidang pertanian yang terus menurun. Meningkatkan kapasitas kerja sehingga luas tanam dan insensitas tanam dapat meningkat.meningkatkan kualitas sehinggaketepatan dan keseragaman proses dan hasil dapat diandalkan serta mutu terjamin, meningkatkan kenyamanan dan keamanan dan keamanan sehingga menambah produksivitas kerja. Meringankan tugas khusus atau sulit dikerjakan oleh manusia dan memberikan peran dalam pertumbuhan di sektor non pertanian (Anonim, 2011).

\subsection{Analisis Usahatani}

Usahatani merupakan suatu himpunan yang bersumber dari alam yang terdapat pada suatu tempat yang diprlukan untuk produk pertanian. Dalam proses produksi terdapat dua komponen yang saling berkaitan yaitu komponen biaya dan pendapatan. Menurut Mubiyarto (1995), bahwa petani akan mendapatkan perhitungan ekonomi antara biaya yang dikeluarkan dan pendapatan yang diperoleh walaupun tidak secara tertulis dan tingginya biaya yang digunakan dalam mengelola usahatani akan berpengaruh terhadap tingkat 
pendaptan yang akan diterima oleh pengelolanya.

\subsubsection{Biaya}

Menurut Mahekan dan Malcom (1991), bahwa biaya produksi merupakan semua pengeluaran yang harus dikeluarkan produksi untuk memperoleh faktorfaktor produksi dan faktor-faktor pnunjang lainnya yang dapat digunakan agar produksi tertentu yang telah direncanakan dalam wujud yang baik.
Pada analisis ini biaya yang dihitung adalah biaya yang secara riil dikeluarkan oleh petani. Berdasarkan penelitian yang dilakukan input yang digunakan hanya berupa biaya operasi yaitu biaya untuk berproduksi. Biaya produksi berupa penyusutan alat, penggunaan saprodi yaitu bibit, pupuk, pestisida, biaya sewa alat, biaya herbisida, biaya Penyusutan alat, biaya tenaga kerja dalam keluarga maupun biaya luar keluarga untuk lebih jelasnya mengenai biaya dan pendapatan pada usahatani padi di kelurahan kempas jaya dapat dilihat pada tabel 3

Tabel 3. Biaya Produksi Pendapatan dan Efesien Usahatani Padi di Kelurahan Kempas Jaya Kec Indragiri Hilir (Rata-rata/ Ha/MT)

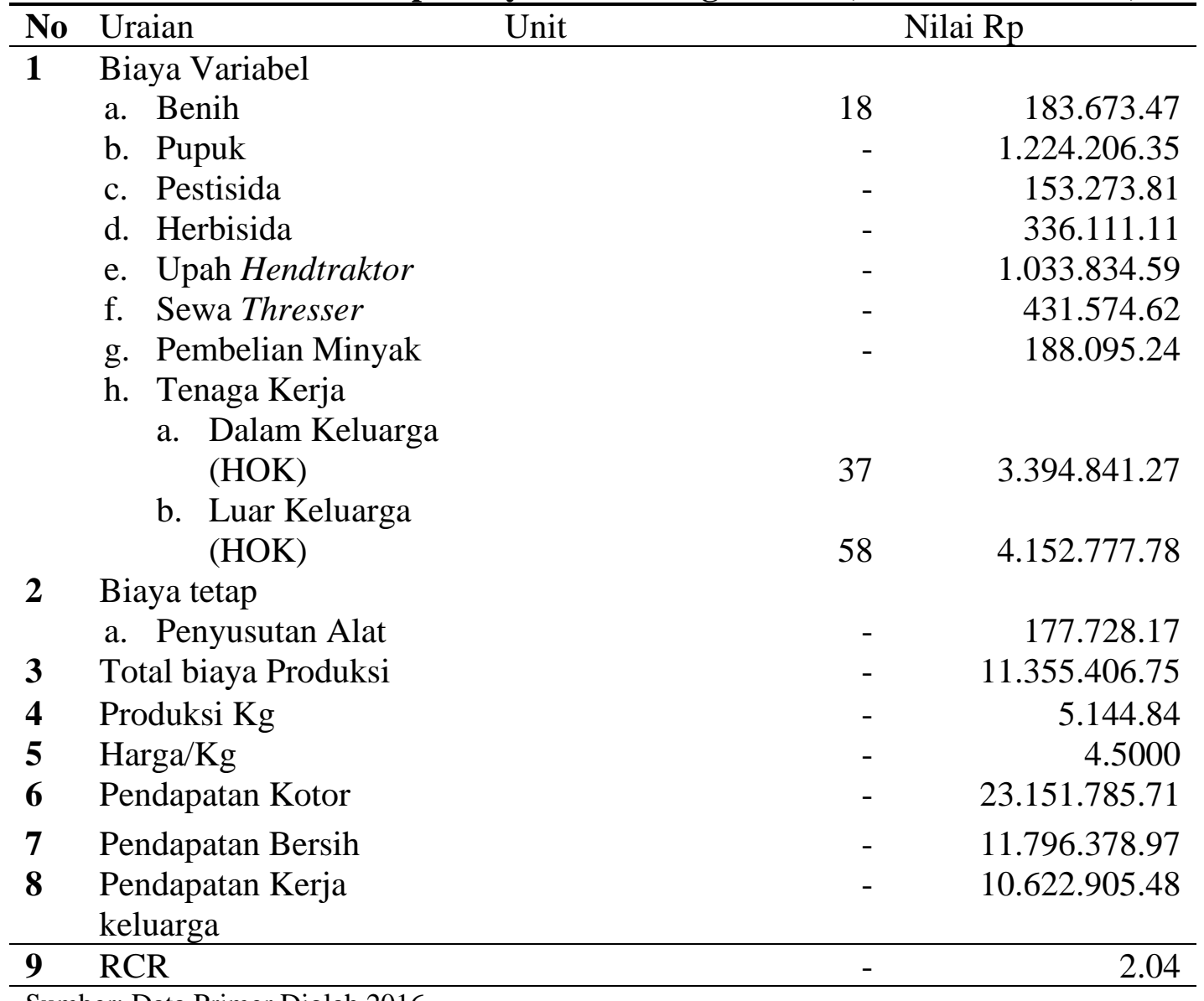

Sumber: Data Primer Diolah 2016

Pada tabel 3 terlihat bahwa rata-rata/ Ha biaya produksi usahatani Sistem tanam jajar legowo sebesar Rp.11.355.406.75/ Ha/MT Dari 
biaya produksi tersebut untuk nilai pupuk yang dikeluarkan sebesar Rp.1.224.206.35/ Ha/MTyang terdiri dari pupuk Urea, Phoska, SP36, nilai rata-rata penggunaan herbisida sebesar Rp. 336.111,11/ Ha/MT nilai rata-rata pestisida Rp. 153.273,81/Ha/MT nilai rata-rata tenaga kerja terbesar yaitu tenaga kerja Luar keluarga (TKLK) Rp. 4.152.777,78 / Ha/MT

Tenaga kerja merupakan faktor produksi padi yang juga dianggap penting bagi petani, karna banyaknya produksi yang dihasilkan tidak hanya dipengaruhi oleh benih, pupuk, pestida melainkan semua faktor itu saling berkaitan seperti sistem yang tidak bisa dipisahkan guna untuk memperoleh produksi yang maksimal. Jumlah produksi yang dihasilkan oleh petani responden sistem tanam jajar legowo rata-rata $5.144,84 \mathrm{Kg} / \mathrm{Ha} / \mathrm{MT}$. Harga yang berlaku saat melakukan penelitian yaitu sebesar Rp.4.500/Kg gabah kering

\subsubsection{Pendapatan}

Besarnya pendapatan yang diterima oleh petani tergantung pada besarnya produksi serta harga jual dan biaya produksi. Prduksi gabah kering yang dihasilkan oleh petani sistem tanam jajar legowo 5:1 sebesar $\quad 5.144,84 \mathrm{Kg} / \mathrm{Ha} / \mathrm{MTdengan}$ jumlah lahan 1 Hektar. Dengan harga jual gabah padi kering (GKK) Rp.4.500/Kg/MT maka rata-rata perluas lahan garapan pendapatan bersih petani berjumlah Rp.11.796.378.97/Ha, sedangkan pendapatan kerja keluarga adalah penjumlahan dari pendapatan bersih, biaya penyusutan alat, dan upah tenagakerja dalam keluarga yaitu sebesar Rp.10.622.905.48 /Ha/MT.
Hasil penelitian yang dilakukan oleh Rauf, dan Amelia (2014) dalam penelitiannya tentang mengetahui pengaruh sistem tanam jajar legowo terhadap pendapatan petani dan kelayakan usahatani padi di Kecamatan Dungaliyyo bahwa produksi yang dihasilkan oleh petani padi sistem tanam jajar legowo 4:1 berjumlah Rp.21.844.604/Ha/MT jika dibandingkan dengan hasil penelitiand di Kelurahan Kempas Jaya bahwa pendapatan petani padi jauh lebih kecil dibandingkan pendapatan petani yang ada di Kecamatan Dungaliyyo, hal ini di sebabkan bahwa petani yang ada di Kelurahan Kempas Jaya masih menggunakan pupuk yang belum maksimal, masih menggunakan bibit yang biasa/tidak bibit ungguldan menggunakan sistem tanam jajar legowo 5:1 sebab itulah produsinya masih rendah.

\subsubsection{Efesiensi Usahatani}

Menurut Soeharjo dan Patong (1973), pendapatan yang besar bukanlah sebagai petunjuk bahwa usahatani efesien. Suatu usahatani dikatakan layak apabila memiliki tingkat efesien penerimaan yang diperoleh atas setiap biaya yang dikeluarkan hingga mencapai perbandingan tertentu. Kriteria kelayakan usahatani dapat diukur dengan menggunakan analisis imbangan penerimaan dan biaya ( R/cRatio Analysis) yang didasarkan pada perhitungan secara finansial. Analisis ini menunjukan besar penerimaan usahatani yang akan diperoleh petani untuk setiap rupiah biaya yang dikeluarkan untuk kegiatan usahatani. Semakin besar nilai $\mathrm{R} / \mathrm{C}$ maka akan semakin besar pula penerimaan usahatani yang diperoleh untuk setiap rupiah biaya 
yang dikeluarkan atau usahatani dikatakan menguntungkn. Kegiatan usahatani dikategorikan layak jika memiliki nilai $\mathrm{R} / \mathrm{C}$ ratio lebih besar dari satu, artinya setiap tambahan biaya yang dikeluarkan akan menghasilkan tambahan penerimaan yang lebih besar daripada tambahan biaya atau secara sederhana kegiatan usahatani menguntungkan. Sebaliknya kegiatan usahatani dikategorikan tidak layak jika memiliki nilai R/C lebih kecil daripada satu, yang artinya untuk setiap tambahan biaya yang dikeluarkan akan menghasilkan tambahan penerimaan yang lebih kecil daripada tambahan biaya atau kegiatan usahatani merugikan. Sedangkan untuk kegiatan usahatani yang memiliki nilai $\mathrm{R} / \mathrm{C}$ ratio sama dengan satu berati kegiatan usahatani berada pada keuntungan normal.

Dalam menjalankan suatu usaha untuk mencapai tujuan akhirnya adalah untuk memperoleh pendapatan yang tinggi denganbiaya yang rendah. Keuntungan yang diterima dapat dijadikan pedoman untuk melanjutkan atau menghentikan kegiatan usaha. Untuk mengetahui keuntungan usaha dapat dilihat dari analisis efesiensi usahatani yang dilakukan oleh petani yang diukur dengan RCR, yaitu perbandingan pendapatan kotor dengan seluruh biaya yang dikeluaran selama proses produksi. Dengan perbandingan ini dapat diketahui berpa besar biaya yang telah dikeuarkan dalam usahatani mampu memberikan pendapatan serta keuntungan yang diperoleh petani..

Berdasarkan hasil penelitian nilai RCR (Ratio Cost Revenue) pada pendapatan usahatani padi sistem tanam jajar legowo di kelurahan kempas jaya rata-rata perhektar nilai $\mathrm{R} / \mathrm{C}$ atas total rata-rata perhektar biaya pendapatan kotor adalah Rp.1,04/MT dan nilai R/C atas total rata-rata perhektar biaya pendapatan bersih adalah Rp.2,04/MT yang artinya bahwa setiap Rp 1.00 biaya yang dikeluarkan akan menghasilkan penerimaan sebesar Rp.2,04 karna kegiatan usahatani sistem tanam jajar legowo ini akan dikategorikan layak sebab memiliki nilai $\mathrm{R} / \mathrm{C}$ ratio lebih besar daripada satu, artinya setiap tambahan biaya yang dikeluarkan akan menghasikan tambahan penerimaan yang lebih besar daripada tambahan biaya atau secara sederhana kegiatan usahatani ini menguntungkan.

\section{KESIMPULAN DAN SARAN}

\subsection{Kesimpulan}

1. Rata-rata hasil produksi usahatani padi sistem tanam jajar legowo yaitu sebesar $5.144,84 \mathrm{Kg} / \mathrm{Ha} / \mathrm{MT}$ dengan pendapatan kotor rata-rata Rp.23.151.785,71 /Ha/MTdan pendapatan bersih sebesar dengan rata-rata Rp.11.974.107,14 / Ha/MT dan pendapatan kerja keluarga sebesar dengan rata-rata Rp.10.622.905,48 / Ha/MT

2. Revenue Ratio (RCR) total biaya adalah Rp. 2,04 yang artinya bahwa untuk setiap Rp.1.00 biaya yang dikeluarkan akan menghasilkan penerimaan sebesar Rp. 2,04 yang berarti mengalami keuntungan.

\subsection{Saran}

Saran dari penelitaian ini adalah agar petani dapat menerapkan 
sistem tanam jajar legowo karena dapat meningkatkan hasil produksi dan dalam RCR juga layak di kembangkan.

\section{DAFTAR PUSTAKA}

Anonimus. 2003. Dinas Pertanian Propinsi Daerah Istimewa Yogyakarta. Dalam: Rakorbangda 2003. Yogyakarta .

AAK. 1992. Budidaya Tanaman Padi. Yogyakarta.

Ahmadi. 2001. Ilmu Pendidikan. Jakarta.

Anonim. 1977. Pedoman Bercocok Tanam Padi Palawija Sayursayuran.

Departemen pertanian.

Badan Pengendalian Bimas. Jakarta

Asda Rauf. 2014. Mengetahuin Pengaruh Sistem Tanam Jajar Legowo Terhadap Pendapatn dan Kelayakan. Gorontalo.

Balai Penelitian Tanaman Pangan. 1992. Prioritas Utama Pembangunan Pertanian.

Birowo. AT. 1974. Aspek-aspek Ekonomi Pertanian dari Masalah Perladangan. Frontir Nomor 2. Lapan Universitas Mulawarman. Samarinda.

Departemen Pertanian. (1993). Kebijakan Teknis Program Pengembangan Usaha
Agribisnis Perdesaan:

Departemen Pertanian. Jakarta.

Dharma. 2009. Tingkat Penerapan Usahatani dan Jenis Varietas Benih Padi Berpengaruh Pada Produsivitas dan Pendapatan Petani.

Djojosumarto. 2008. Teknik Aplikasi Pestisida Pertanian . Kanisius Yogyakarta.

Hernanto. 1994. Ilmu Usahatani. Jakarta.

Irman Dan Syarifudin. 2005. Metode Penelitian Bisnis. Sumatra Utara UISU.

Legiyo. 2012. Tegnologi Budaya Padi Varietas unggul Pada Lahan Pasangs Surut Kabupaten Indragiri Hilir. Badan Pelaksanaan Penyuluh dan Ketahanan Pangan Kab. Inhil.

Makeham and Malcolm. 1991. Manajemen Usahatani daerah Tropis. LP3ES. Jakarta.

Mosher. AT. 1991. Menggerakan dan Membangun Pertanian. Penerbit BPFE. Edisi Pertama. Jakarta.

Noor. M. 1996. Padi Lahan Marginal. Penebar Swadaya. Jakarta.

Novizar. N. 2000. Budidaya dan Proses Diversifikasinya. Yayasan Hutanku. Padang. 